\title{
Structural Characterization and Surface Modification of Titanium Plates After Nd:YAG Laser Treatment
}

\author{
A. Bahloul ${ }^{a, *}$, M.C. Sahour ${ }^{b}$, R. Oumeddour ${ }^{a}$ and G. Pillon ${ }^{c}$ \\ ${ }^{a}$ Laboratory of Industrial Analysis and Materials Engineering. University May 8, 1945, P.O. \\ Box 401, Guelma, 24000, Algeria \\ ${ }^{b}$ Department of Material Sciences, Faculty of Mathematical, Informatics and Material Science. \\ University May 8, 1945, P.O. Box 401, Guelma, 24000, Algeria \\ ${ }^{\mathrm{C}}$ Interdisciplinary Laboratory of Carnot de Bourgogne (ICB). \\ University of Bourgogne, Franc
}

Received January 15, 2018 ; accepted July 18, 2018

\begin{abstract}
Surface laser treatments of commercially pure titanium plates (CP-Ti grade 4) were performed in air using a Nd:YAG laser source of short pulse duration about $5 \mathrm{~ns}$. Attention is drawn to the following laser-processing parameters: laser-power interaction time and surface of the irradiated zone. The morphology, structure and chemical composition of the formed layers were analyzed by different characterization techniques providing physico-chemical and structure information.

The objective of this research was to study the influence of laser fluence on the composition of the CP-Ti grade 4. Additionally, it was pretended to evaluate the surface modification of obtained layers.

The electrochemical response of modified surface in Ringer's physiological solutions at varying $\mathrm{pH}$ values was studied. Fretting test has been investigated in order to study the tribological behavior of the laser treated surface.

Results showed that the laser treatments induce the insertion of light elements such as $\mathrm{O}_{2}$ and $\mathrm{N}_{2}$.

Laser surface processing shifted the corrosion potential of CP-Ti grade 4 towards the noble side, as compared to the untreated one. After fretting tests, it was found that the steady friction coefficient was similar for all the layers, and quite lower than that measured for the untreated CP-Ti.
\end{abstract}

Keywords: Titanium, Nd:YAG laser, surface modification, oxynitrides, corrosion, fretting.

\section{Introduction}

Titanium and its alloys have gained acceptance over the years in automobile, aerospace, marine, medicine, chemical and energy industries [1-4]. The corrosion

\footnotetext{
*Corresponding author. E-mail address: abida_bahloul@yahoo.fr, israbah@yahoo.fr
} 
resistance in physiological solutions which model human body fluid is one of the basic criteria to choose that material as an implant.

Titanium-based alloys possess an attractive combination of low density, moderately high strength and good aqueous corrosion resistance for industrial and technological applications [5].

Laser as a source of heat has been successfully employed to modify the microstructure and/or composition of the near surface region of a component, to improve wear corrosion and oxidation resistance of commercial metals [6]. This technique has many advantages, as it allows rapid melting, intermixing and solidification in the alloyed zone, confined to a relatively shallow depth from the surface, within a very short interaction time [5].

Laser treatments are powerful tools for improving the mechanical, chemical and optical properties of metals and alloys. Both laser surface melting (LSM) and laser surface alloying (LSA) of structural materials have brought improvement in the corrosion and tribological properties of the latter.

The surface of titanium targets can be modified by a variety of laser treatments carried out in air. Colors, going from yellow to purple, blue or green, were obtained as a function of the imposed laser fluence. Different compounds are likely to be formed: oxides, which may be used for tribological purposes [7] or for coloring [8], and nitrides, for their hardening properties. It was shown that the surface state of a material is strongly influenced by the laser treatment parameters: oxygen insertion during laser irradiation of the titanium surface is mainly influenced by the repetition rate, while nitrogen insertion is controlled by laser fluence [9-11].

From an applicative point of view, it is of particular interest to obtain, in a simple process, titanium oxynitrides, at mixed phases, which combine the stability of titanium oxides and the hardness of titanium nitrides. It is worth noting that the roughness is sensitive to pulse duration. It was shown that the layers obtained with short pulse $(5 \mathrm{~ns})$ have lower roughness than the layers obtained with a longer one (35 ns) [12]. Moreover, with constant pulse duration, an increase in the laser fluence induces an increase in the roughness.

In this work, we analyzed the influence of the laser fluence value, varying from 8 $\mathrm{Jcm}^{-2}$ to $14 \mathrm{~J} \mathrm{~cm}^{-2}$, on the composition of the CP-Ti grade 4, and we compared the surface of the obtained layers with that of the untreated CP-Ti grade 4 .

\section{Experimental detail}

\section{Laser treatments of CP-Ti plates}

Commercially pure titanium (grade 4) samples of dimensions $15 \mathrm{~mm}$ x $10 \mathrm{~mm}$ x 1. $2 \mathrm{~mm}$ were used. Prior to laser treatment, the sample surface was mechanically polished, in order to remove the contaminants and the surface oxide layer, and to obtain a reference surface with very low roughness $(\mathrm{Ra}<0.4 \mu \mathrm{m})$.

The laser treatments were performed in air, using a Nd:YAG Q-switched laser (Quantel Brilliant B model), with a wavelength of $\gamma=1.064 \mu \mathrm{m}$, which generates a pulse duration of $\tau_{1}=5 \mathrm{~ns}$, at a repetition rate of $\mathrm{f}=10 \mathrm{~Hz}$. The laser beam was focused on the sample mounted on a numerically controlled $\mathrm{X}-\mathrm{Y}$ table. The 
amount of laser radiation absorbed onto a material depends on the absorption coefficient of that material, and it can vary due to parameters such as temperature of the work piece and surface roughness [13].

The focused laser with a diameter of about $1.6 \mathrm{~mm}$ was moved over the titanium substrate surface with a velocity ( $v$ ) going from 100 to $165 \mathrm{~mm} \mathrm{~s}^{-1}$, to form parallel straight lines. The laser fluence per pulse, $\mathrm{F}_{\mathrm{lp}}\left(\mathrm{Jcm}^{-2}\right)$, can be calculated by the following relation:

$$
\mathrm{F}_{\mathrm{lp}}=\mathrm{P}_{\mathrm{l}} / \mathrm{A} \mathrm{f}
$$

where $P_{1}$ is the average laser power (in W), $A$ is the laser spot area (in $\mathrm{cm}^{2}$ ) and $\mathrm{f}$ is the repetition rate (in $\mathrm{s}^{-1}$ ).

The distance, $\mathrm{d}$, between adjacent lines, was varied from 0.15 to $0.27 \mathrm{~mm}$, by changing the mean laser fluence per pulse, $F_{l p}$, and the number of impacts, $n_{p}$; layers of various colors were formed on the target surface.

The cumulated laser fluence, $\mathrm{F}_{1}$ (in $\mathrm{Jcm}^{-2}$ ), corresponding to the total energy per surface unit, can be calculated by the following equation:

$$
\mathrm{F}_{\mathrm{l}}=\mathrm{F}_{\mathrm{lp}} \times \mathrm{n}_{\mathrm{p}}
$$

\section{Electrochemical tests}

For electrochemical studies, coupons of $10 \mathrm{~mm} \times 10 \mathrm{~mm} \times 2 \mathrm{~mm}$ were cut from the laser treated plates. The specimens were then washed in distilled water, followed by ultrasonic cleaning in acetone for $30 \mathrm{~min}$. These tests were carried out in the Ringer's physiological solutions at $\mathrm{pH}=4.0$ and 9.0 , which simulate the severe conditions from the human bio fluid, in the case of surgery (acid values) or inflammations and infections (alkaline values) [14-18]. This was done to evaluate the effect of $\mathrm{pH}$ on laser treated specimens. The Ringer's solution was prepared by adding $9.0 \mathrm{~g} / \mathrm{L} \mathrm{NaCl}, 0.17 \mathrm{~g} / \mathrm{L} \mathrm{CaCl}_{2}, 0.14 \mathrm{~g} / \mathrm{L} \mathrm{KCl}$ and $2.0 \mathrm{~g} / \mathrm{L}$ $\mathrm{NaHCO}_{3}$ (grade chemicals) to distilled water. The $\mathrm{pH}$ of the solutions was maintained by adding the requisite amount of $\mathrm{NaOH}$ or $\mathrm{HCl}$ [19]. The solution during polarization tests was maintained at $37 \pm 2{ }^{\circ} \mathrm{C}$, to simulate the body temperature. Measurements in the Ringer's solution were conducted under a nitrogen atmosphere. A standard three-electrode cell was used for electrochemical tests. The laser treated sample was set as working electrode, while a saturated calomel electrode (SCE) and a platinum wire were used as reference electrode and counter electrode, respectively. The polarization experiments were carried out by scanning the specimens (towards noble potentials) at $1.0 \mathrm{mV} / \mathrm{s}$ from $-200 \mathrm{mV}$, with respect to open circuit potentials (OCP), and reversing the scan from transpassive potential. The tests were repeated twice for each specimen. The experiments were performed with an EG\&G Potentiostat/Galvanostat (Princeton Applied Research) Model 273A, driven by powersuite software.

\section{Fretting test preparation}

Fretting tests were done at room temperature, without lubrication. The contact geometry was a cylinder on a plane. The sample after immersion for $1500 \mathrm{~h}$ in 
Ringer's solutions was fixed on a rigid frame, whereas the cylinder (bearing steel) was connected to the piston of a tensile-compressive servo-hydraulic equipment moving at an imposed displacement $(\mathrm{D}= \pm 90 \mu \mathrm{m})$ and chosen frequency $\left(f=20 \mathrm{~Hz}\right.$ ). $F_{n}$ was the normal load, and it was continuously recorded during the tests and applied via a loading rectangle $(\mathrm{Fn}=18 \pm 2 \mathrm{~N})$, leading to a contact pressure of $120 \pm 10 \mathrm{MPa}$. The tangential load $\left(\mathrm{F}_{\mathrm{t}}\right)$ was continuously recorded as a function of the relative displacement (D). This recording led to the plot of $\mathrm{F}_{\mathrm{t}^{-}} \mathrm{D}$ curves all throughout the test [20]. The friction coefficient, $\mu$, was determined from the following relation:

$$
F_{t}=\mu F_{n}
$$

The fretting tests were carried out at a constant average contact pressure of 130 $\mathrm{MPa}$. The cylinder was fabricated from $100 \mathrm{Cr}_{6}$ steel, with a hardness of HRC 60.

The measured force, $\mathrm{F}_{\mathrm{t}}$, and the displacement amplitude were acquired and processed by specific software. Fretting tests were done with a finite number of cycles varying from $3.10^{3}$ to $2.10^{4}$ cycles.

In this work, we analyzed the evolution of the friction coefficient, $\mu$, as a function of the number of cycles, $\mathrm{N}$.

\section{Structural characterization}

Optical and scanning electron microscopy (equipped with an EDS microprobe) studies were done with a JEOL JSM 6400F, typically working at $20 \mathrm{KeV}$. The phases which were present on the surface of the treated sample were analyzed by $\mathrm{X}$-ray diffraction using the $\mathrm{K} \alpha(\mathrm{Cu})$ radiation, with angles that varied from $0.5^{\circ}$ $8^{\circ}$, in order to control the average depth penetration of the X-ray radiation in the substrate.

\section{Results and discussion}

\section{Morphology and composition of the treated layers}

When the laser fluence is high enough, melting and superheating of the liquid are possible. The existence of a thin molten pool during the laser treatment was confirmed by the SEM observation of the layers surface (Fig. 1), showing projections lengthened by droplets, and some cracks. Cross-sectional observations show that the depth affected by the laser treatment was of about 2 $\mu \mathrm{m}$. By varying the cumulated laser fluence, layers of various colors were formed on the target surface. The laser treated conditions used in this work led to small quantities of ejected material around the treated zone. We attributed this to recoil pressure generated by the ejection of matter at the heart of the impact where the laser intensity was the greatest. So, the molten metal was pushed back on the sides of the impact.

The EDS analysis of cross-sections shows that there was no nitrogen and oxygen at about $3 \mu \mathrm{m}$ below the surface. 
The chemical composition of the treated layers was also not really uniform (Fig.1).

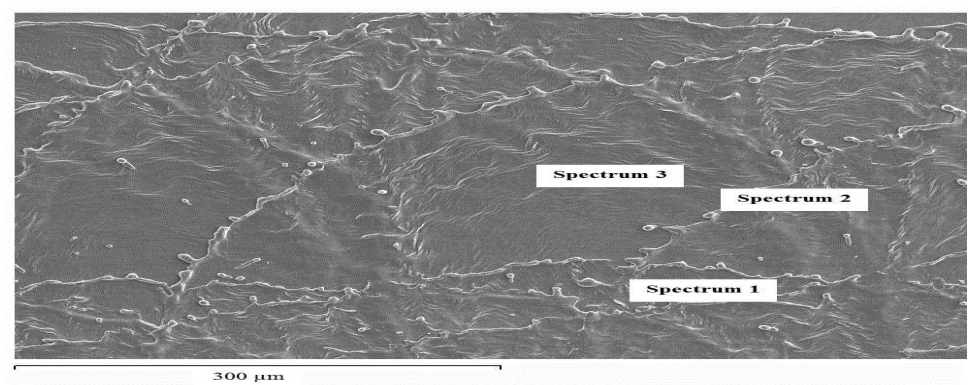

Figure 1. SEM top view of a sample $(60 \mu \mathrm{m})$ obtained with laser fluence $\mathrm{F}_{1}=400 \mathrm{Jcm}^{-2}$.

It has been shown that the laser surface treatment induced the insertion of light elements such as oxygen $(\mathrm{O})$ and nitrogen $(\mathrm{N})$ in the treated layer, which all had a role in the forming phases. Table 1 summarizes the chemical composition of the treated layers.

Table 1. Chemical composition of the treated layer.

\begin{tabular}{|c|c|c|c|c|}
\hline \multirow[b]{2}{*}{ Spectrum } & \multicolumn{3}{|c|}{ Elements (at \%) } & \multirow[b]{2}{*}{ Total } \\
\hline & $\mathbf{N}$ & $\mathbf{O}$ & $\mathbf{T i}$ & \\
\hline Spectrum 1 & 9.33 & 15.35 & 75.32 & \multirow{2}{*}{100.00} \\
\hline Spectrum 2 & 9.56 & 19.36 & 71.08 & \\
\hline Spectrum 3 & 10.52 & 29.80 & 59.68 & \multirow{2}{*}{100.00} \\
\hline Max. & 10.52 & 29.80 & 75.32 & \\
\hline Min. & 9.33 & 15.35 & 59.68 & 100.00 \\
\hline
\end{tabular}

The laser fluence was varied from 8 to $14 \mathrm{Jcm}^{-2}$, and the color of the layers changed to yellow for low laser fluencies below $9 \mathrm{~J} \mathrm{~cm}^{-2}$, and to blue and purple for higher fluencies above $10 \mathrm{~J} \mathrm{~cm}^{-2}$. Moreover, the morphology, the structure and the chemical compositions of the layers were also modified. The insertion of nitrogen and oxygen seemed to vary as a function of the laser fluence. The nitrogen and oxygen amount increased with a higher laser fluence (Table 2).

By increasing the laser fluence, the oxygen amount increased from around 35.16 at.\% up to 40.20 at.\%, which corresponds to the growth of stoichiometric titanium dioxide $\left(\mathrm{TiO}_{2}\right)$. For higher laser fluence values, the content in nitrogen (N) and oxygen (O) slightly increased, up to about 20.21 at.\% for a laser fluence of 8 to $14 \mathrm{~J} / \mathrm{cm}^{2}$. The insertion of nitrogen $(\mathrm{N})$ and oxygen $(\mathrm{O})$ increased with the fluence laser.

Table 2. Laser treatment conditions and color of the layers analyzed in this work.

\begin{tabular}{lccc}
\hline Specimens & LSA 1 & LSA 2 & LSA 3 \\
\hline $\mathrm{P}_{1}(\mathrm{~W})$ & 1 & 2 & $2.5-2.90$ \\
$\mathrm{~F}_{1 \mathrm{p}}\left(\mathrm{J} \mathrm{cm}^{-2}\right)$ & 8 & 10 & $11-14$ \\
Color & Yellow & Blue & Purple \\
Elements & & & \\
$\mathrm{N}($ at.\%) & 14.05 & 19.90 & 20.21 \\
$\mathrm{O}($ at. \%) & 35.16 & 40.10 & 40.20 \\
Ti (at.\%) & 50.79 & 40.00 & 39.59 \\
\hline
\end{tabular}


$\mathrm{P}_{1}(\mathrm{~W})$ is the average laser power and $\mathrm{F}_{1 \mathrm{P}}\left(\mathrm{J} \mathrm{cm}^{-2}\right)$ is the laser fluence per pulse. A detailed study of the surface of the samples by 3D microscopy (AliconaInfinite Focus) revealed that the spatial distribution of the color was not really uniform (Fig. 2).

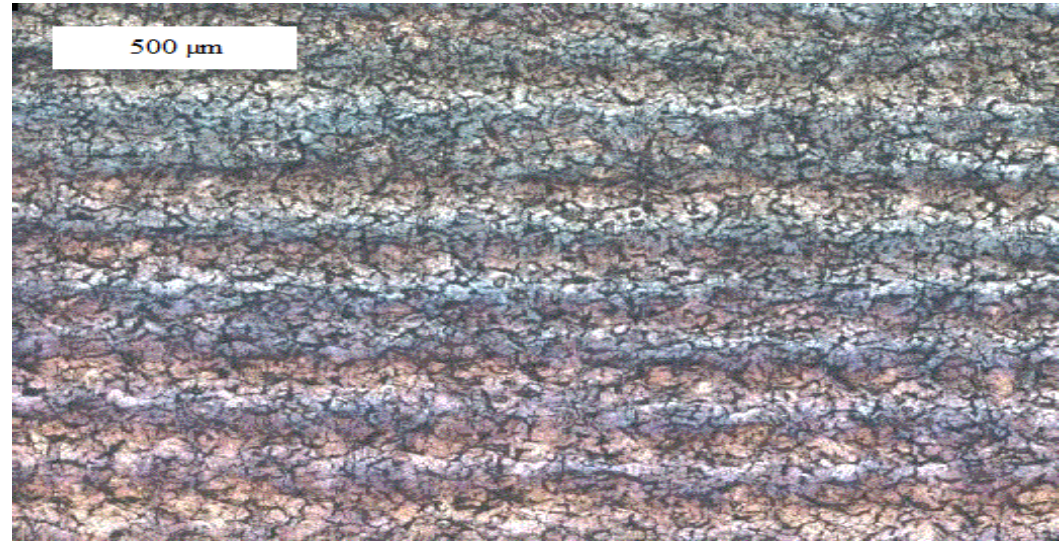

Figure 2. Micrograph $(500 \mu \mathrm{m})$ showing the non-uniformity of the spatial color.

Treated surfaces images were created with the Alicona Company. 3 D view (Fig. 3) illustrates the general morphology and surface topography of the treated sample obtained with $8.5 \mathrm{~J} / \mathrm{cm}^{2}$. The treated surfaces are characterized by linear, parallel scares due to laser scanning. The distance between two consecutive scanning lines $(100 \mu \mathrm{m})$ corresponds to the laser beam diameter. The evolution in surface roughness confirms that the target surface has been heated to the liquid phase. The roughness measurements of the surface layer have been carried out. The value of the surface roughness was $2.04 \mathrm{~nm}$.

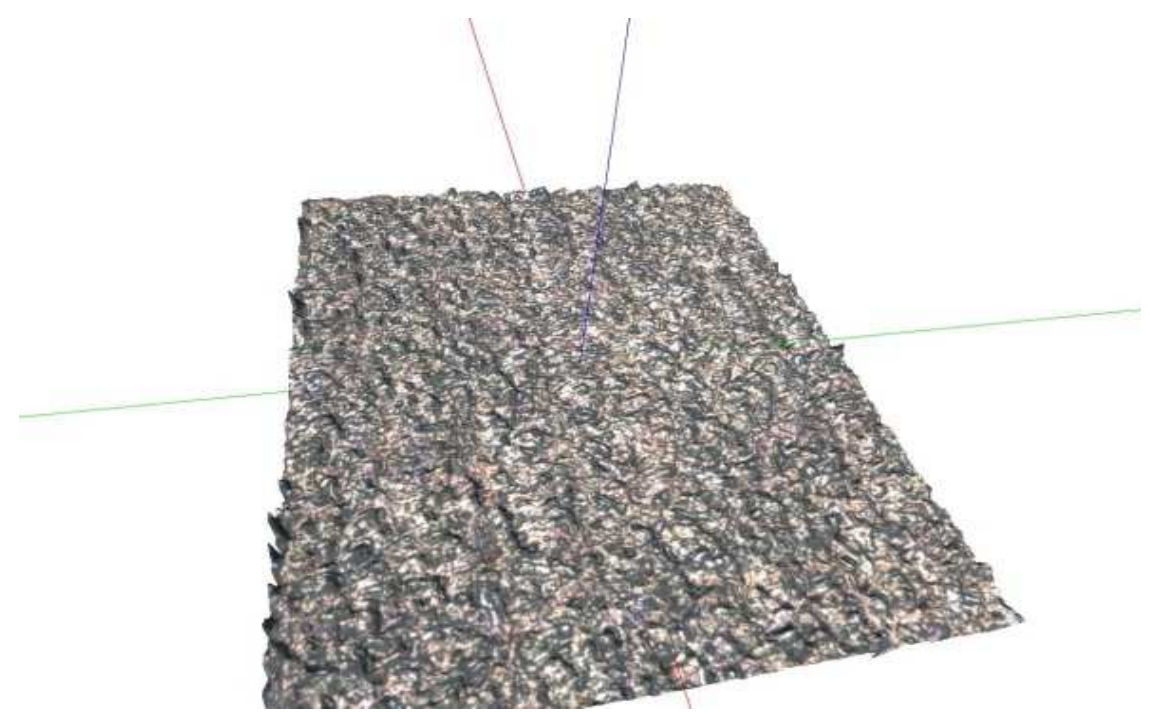

Figure 3. 3 D image showing the surface topography of the treated sample.

Fig. 4 represents the three dimensional view of the surface roughness corresponding to the above treated surface. The obtained profile shows a centered part more hollowed out than the peripheral one. This difference can be attributed to the heterogeneous distribution of the laser energy in the treated surface. 


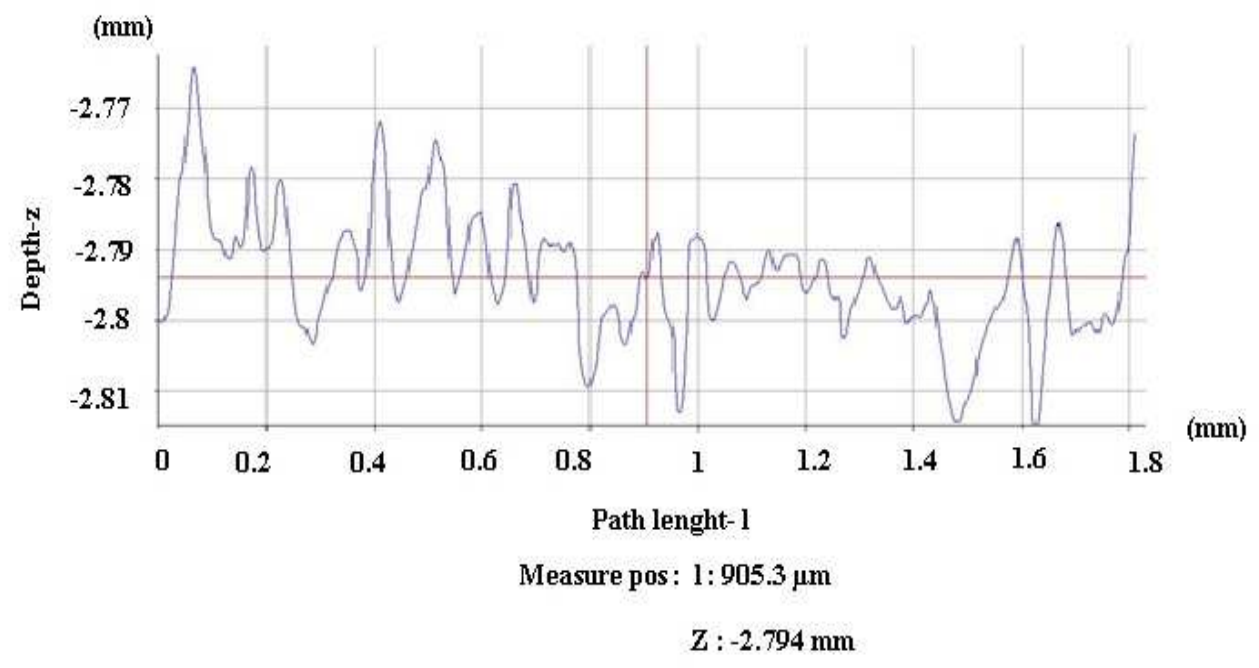

Figure 4. Profile obtained with a $3 \mathrm{D}$ optical microscope for the treated surface.

\section{$X R D$ analysis}

An XRD $(\theta-2 \theta)$ analysis shows that the substrate, which had not been irradiated, appeared to be titanium under stress resulting from electrochemical polishing. The XRD pattern of non-irradiated Ti shows peaks only corresponding to the $\alpha$-Ti phase (Fig. 5).

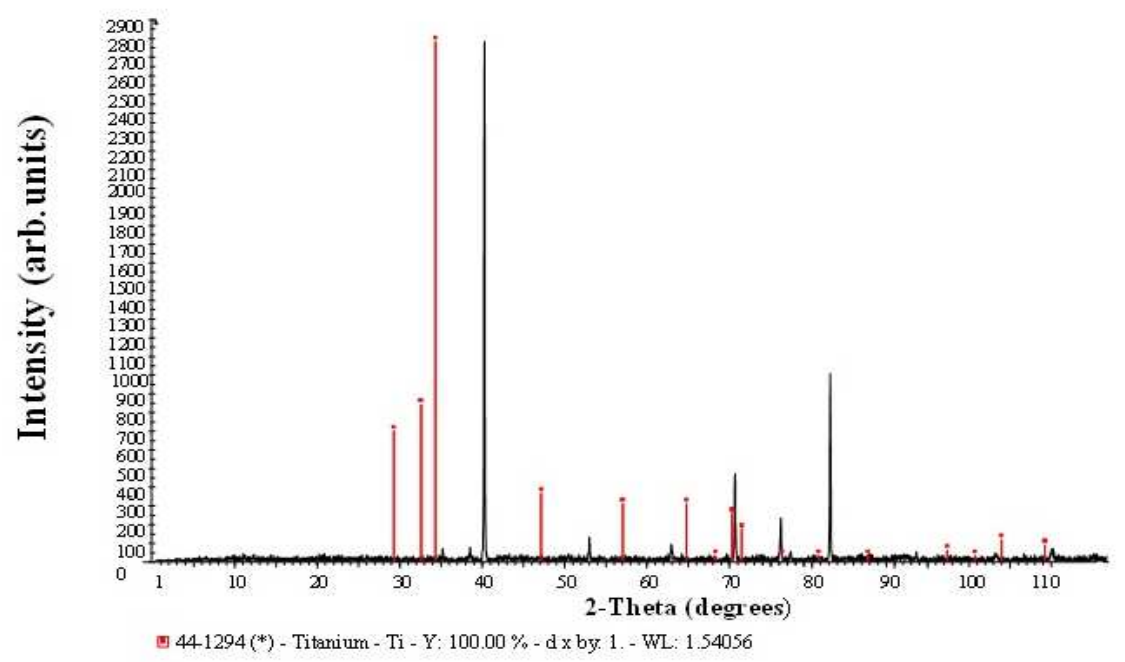

Figure 5. XRD spectrum of non-irradeated Ti.

The competition between $\mathrm{O}_{2}$ and $\mathrm{N}_{2}$ explains the evolution composition of the layers during laser treatments. This evolution indicates that the laser fluence controlled the layers morphology and the phase's formation.

An XRD pattern of the sample obtained, with a laser fluence $F_{1}=350 \mathrm{~J} \mathrm{~cm}^{-2}$ (Fig. 6), denotes peaks corresponding to an hexagonal phase:

$\mathrm{Ti}_{3} \mathrm{O}$ (fiche JCPDS 76-1644); titanium oxide (TiO) (fiche JCPDS 08-0117), titanium (Ti) and titanium nitride ( $\mathrm{TiN}_{0.26}$ ); and phase with cubic symmetry (face centered cubic phase) TiN (fiche JCDPS 38-1420). 


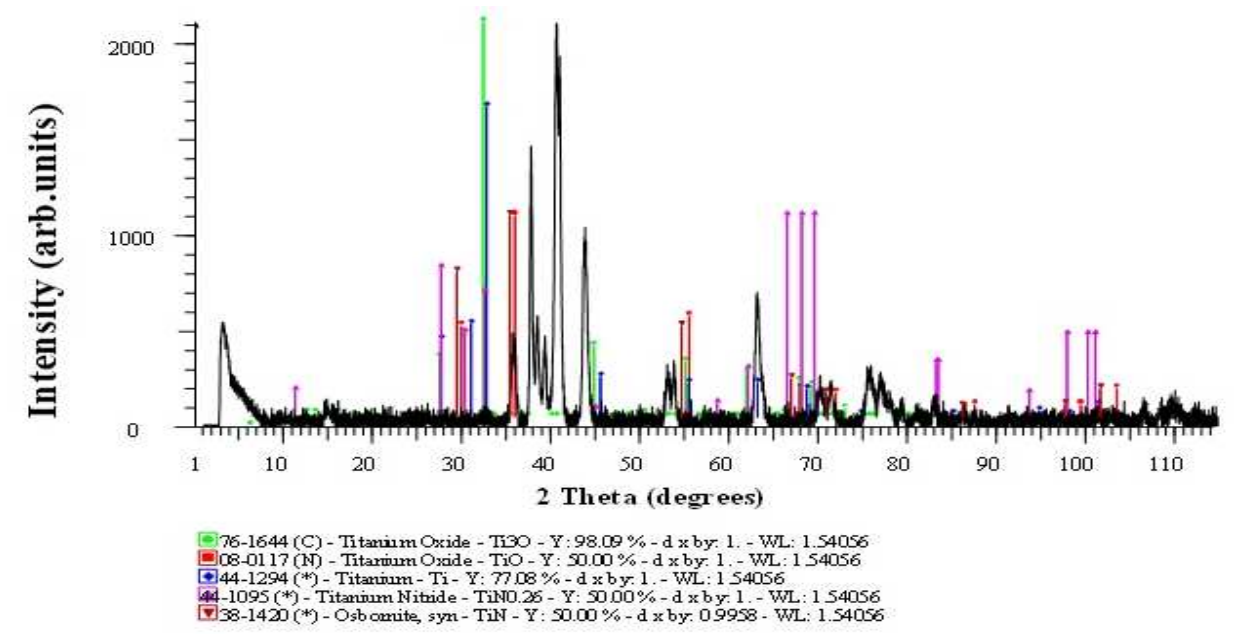

Figure 6. XRD pattern of the sample obtained with a laser fluence $F_{1}=350 \mathrm{Jcm}^{-2}$.

The X-ray diffraction patterns of the target surface show the presence of various phases.

According to the titanium/oxygen phase equilibrium diagram, several phases can be obtained during the thermal treatment [21].

TiN seemed to be present only when the material surface was vaporized at extremely high temperatures [22-23]. The intense laser irradiation heated and melted the titanium surface and the plasma formed on the top of the surface, resulting in the dissociation of nitrogen and in diffusion into the melt. After laser irradiation, solidification began, and different TiN developed with different counts of nitrogen $(\mathrm{N})$. The layers can be considered as gradient layers formed by TiN, TiN+TiN 0.26 and $\alpha-\mathrm{Ti}+\mathrm{N}$. It is worth noting that nitrogen was inserted in significant quantity in melt titanium with a plasma plume above it, which excites and even dissociates the nitrogen molecules, as well as the ablated Ti. Also, gasatoms were ionized, whereas the very reactive oxygen in the air directly combined with titanium, either on the target, or immediately on contact with the titanium vapor present in the plasma plume.

The target was therefore submitted to a very abrupt heating and cooling rate of about $3.10^{6} \mathrm{Ks}^{-1}$, leading to non-equilibrium phenomena. Layers were distinguished by their color and also by their roughness.

\section{Electrochemical characterization}

Open circuit potential was employed to investigate the corrosion performance of (CP-Ti grade 4 ) after laser modification. The corrosion current density $\left(i_{\text {corr }}\right)$ was determined from the intersection of the respective anodic and cathodic Tafel slopes.

The corrosion resistance of biomedical grade metallic implants, such as titanium and its alloys, is a very important issue in the biomaterials field. These implants are in incessant contact with the physiological fluid, which is rich in chloride ions able to promote metal oxidation. In order to evaluate the behavior of the laser treated specimens in a physiological medium, experiments of corrosion were performed in the Ringer's solution. Polarization measurements were carried 
out in order to gain knowledge regarding the kinetics of the cathodic and anodic reactions.

Fig. 7 shows the corrosion potentials $\left(\mathrm{E}_{\mathrm{corr}}\right)$ as a function of time for untreated and treated CP-Ti grade 4 in the Ringer's solutions of $\mathrm{pH}$ (a) 9.0 and (b) 4.0, which were compared as a control. The electrochemical reactions at the metalelectrolyte interface varied with time. The $E_{\text {corr }}$ initially increased until the passive film reached its limiting protective capacity, after which it stabilized. It can be also observed that the value of the $\mathrm{E}_{\text {corr }}$ for the untreated CP-Ti grade 4 was more negative than that of the treated CP-Ti grade 4 in both Ringer's solutions of $\mathrm{pH}=9.0$ and 4.0 .
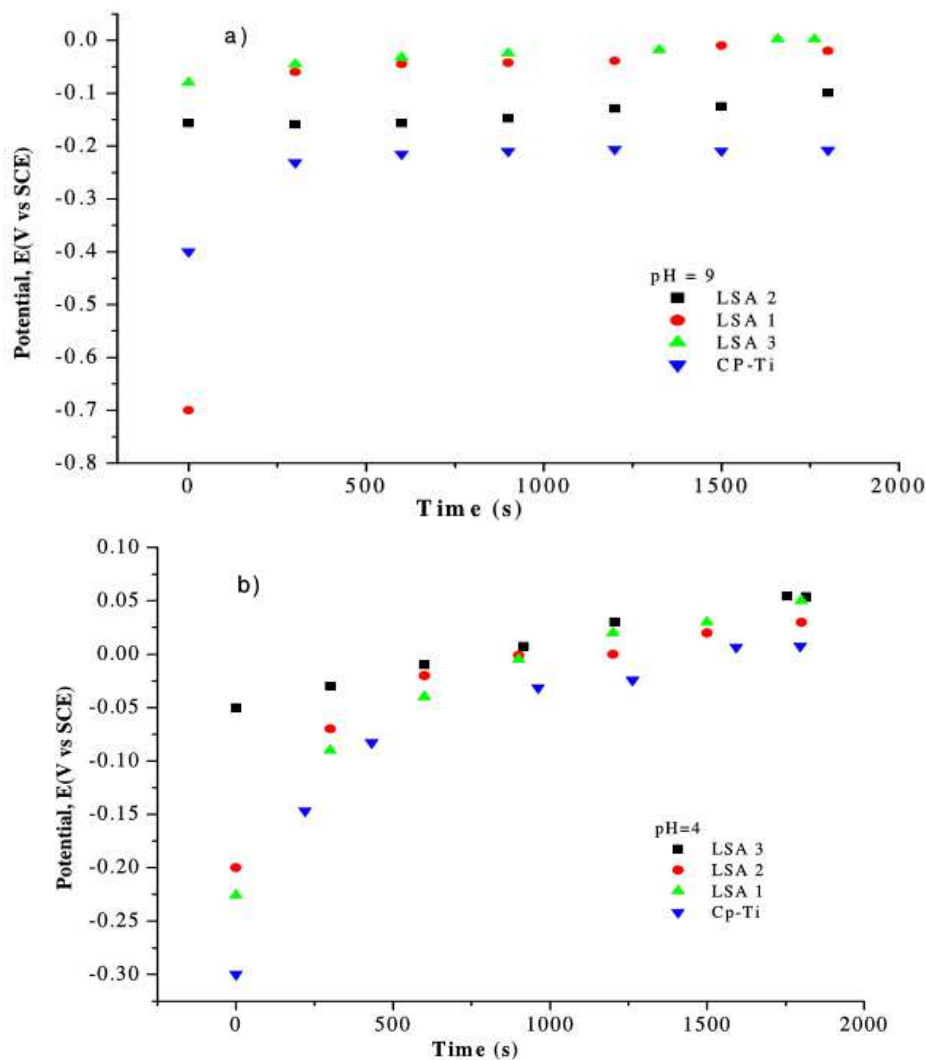

Figure 7. Corrosion potential. Variation of time of untreated and treated CP-Ti grade 4 in Ringer's solutions of pH (a) 9.0 and (b) 4.0.

In the solution of $\mathrm{pH}=9.0$, the initial $\mathrm{E}_{\text {corr }}$ for LSA 1 was approximately -0.7 V/SCE. It rapidly increased and stabilized in the region of $-0.06 \mathrm{~V} / \mathrm{SCE}$, after 30 min. Similarly, the initial $\mathrm{E}_{\text {corr }}$ for LSA 2 was approximately $-0.157 \mathrm{~V} / \mathrm{SCE}$, and it stabilized to nearly $-0.1 \mathrm{~V} / \mathrm{SCE}$, after $30 \mathrm{~min}$. The initial $\mathrm{E}_{\text {corr }}$ for LSA 3 was approximately $-0.08 \mathrm{~V} / \mathrm{SCE}$, and rapidly increased to more noble potentials, compared with the two aforementioned samples. It stabilized at the region of $0.006 \mathrm{~V} / \mathrm{SCE}$, after $30 \mathrm{~min}$.

In the solution of $\mathrm{pH}=4.0$, LSA 1 and LSA 2 exhibited values between those of LSA 3 and CP-Ti grade 4 . The initial $E_{\text {corr }}$ for LSA 3 was $-0.05 \mathrm{~V} / \mathrm{SCE}$, and it rapidly increased and stabilized in the region of $+0.054 \mathrm{~V} / \mathrm{SCE}$, after $30 \mathrm{~min}$. CPTi grade 4 exhibited the lowest initial $E_{\text {corr. }}$ It showed values as low as -0.3 $\mathrm{V} / \mathrm{SCE}$, and a stabilized potential near $0.007 \mathrm{~V} / \mathrm{SCE}$. 
The polarization curves obtained for untreated and treated CP-Ti grade 4 in Ringer's solutions of $\mathrm{pH}$ (a) 9.0 and (b) 4.0 are shown in Fig. 8. Table 3 comprises the corrosion potential $\left(\mathrm{E}_{\mathrm{corr}}\right)$ and current density ( $\left.\mathrm{i}_{\text {corr }}\right)$ values taken from the corresponding Tafel's curves of Fig. 8.
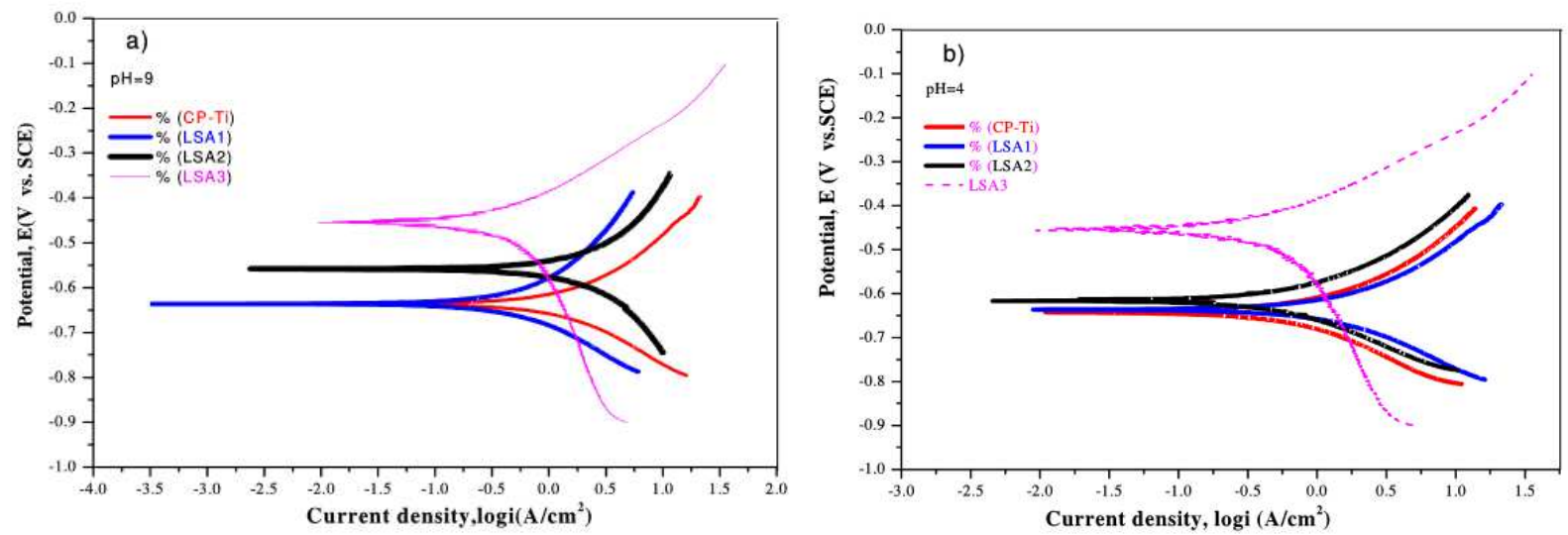

Figure 8. Potentiodynamic polarization curves of untreated and treated CP-Ti grade 4 in Ringer's solutions of $\mathrm{pH}$ (a) 9.0 and (b) 4.0.

Table 3. Corrosion potential $\left(E_{\text {corr }}\right)$ and current density ( $\left.i_{\text {corr }}\right)$ determined from the polarization curves in Fig. 8.

\begin{tabular}{lcccc}
\hline \multirow{2}{*}{ Specimens } & \multicolumn{2}{c}{$\mathbf{p H = 4}$} & \multicolumn{2}{c}{$\mathbf{p H = 9}$} \\
\cline { 2 - 5 } & $\begin{array}{c}\mathbf{E}_{\text {corr }} \\
(\mathbf{V} / \mathbf{S C E})\end{array}$ & $\begin{array}{c}\mathbf{I}_{\text {corr }} \\
\left(\boldsymbol{\mu} \mathbf{A} / \mathbf{c m}^{2}\right)\end{array}$ & $\begin{array}{c}\mathbf{E}_{\text {corr }} \\
(\mathbf{V} / \mathbf{S C E})\end{array}$ & $\begin{array}{c}\mathbf{I}_{\text {corr }} \\
\left(\boldsymbol{\mu} \mathbf{A} / \mathbf{c m}^{2}\right)\end{array}$ \\
\hline CP-Ti & -0.490 & 1.355 & -0.645 & 0.961 \\
LSA 1 & -0.560 & 0.650 & -0.645 & 0.271 \\
LSA 2 & -0.460 & 0.219 & -0.560 & 0.286 \\
LSA 3 & -0.639 & 0.206 & -0.450 & 0.275 \\
\hline
\end{tabular}

According to the potentiodynamic polarization curves or Tafel curves in Fig. 8, the laser treatment caused the corrosion potential ( $E_{\text {corr }}$ ) of CP-Ti grade 4 to shift towards a positive direction, in Ringer's solutions, at $\mathrm{pH}=4.0$ and $\mathrm{pH}=9.0$. After the laser treatment, the $\mathrm{E}_{\text {corr }}$ for LSA 2 and LSA 3 samples became more positive than the one for the untreated $\mathrm{CP}$-Ti grade 4 . The maximum shift observed was $-0.450 \mathrm{~V} / \mathrm{SCE}$ in the solution of $\mathrm{pH}=9.0$, revealing that the anticorrosion performance was superior to that of the other samples. The optimum dose of nitrogen was observed (20.21 at.\%) for the best corrosion resistance.

The $\mathrm{E}_{\mathrm{corr}}$ of the untreated specimen became more active with an increase in $\mathrm{pH}$ values (more alkaline). This can be explained due to the variation in the redox potential of oxygen (present in the solution) with $\mathrm{pH}$ values, according to the following equation:

where Nernst equation

$$
1 / 2 \mathrm{O}_{2}+2 \mathrm{H}^{+}+2 \mathrm{e}^{-} \rightarrow \mathrm{H}_{2} \mathrm{O}
$$

$$
\mathrm{E}(\mathrm{V})=\mathrm{E}^{\circ}\left(\mathrm{O}_{2} / \mathrm{H}_{2} \mathrm{O}\right)-0.059 \mathrm{pH}
$$


is $\mathrm{pH}$ dependent. It is clear from this equation that the increase in $\mathrm{pH}$ values will result in the more active (negative) redox potential of the oxygen-reduction that governs the corrosion kinetics in such solutions [20].

When the current density ( $i_{\text {corr }}$ ) was analyzed, lower values were represented by the metallic substrates treated with laser, indicating an improvement in the corrosion resistance, which is shown in Table 3 and Fig. 8. The formed layer prevents somehow the diffusion of oxidative species such as $\mathrm{H}^{+}$, oxygen, and even water, from the aqueous medium to the metallic surface. This behavior led to a lower current density, since the availability of the components responsible for the oxidation may have been reduced. The corrosion resistance may be attributed to the $\mathrm{N}$ content in the obtained layers. The $\mathrm{Cl}$ ions presence in the above system (as in the present situation), however, may disrupt the $\mathrm{TiO}_{2}$ film, consequently producing a localized solution chemistry (such as a strong acid with a high $\mathrm{Cl}^{-}$concentration) favorable for corrosion. In the lower $\mathrm{pH}$ solutions $(\mathrm{pH}=$ 4.0), such aggressive conditions may easily lead to an early break down of the passive film, compared to the alkaline solutions.

Thus, surface laser treatments of commercially pure titanium were a suitable anti-corrosive technique in the physiological solution, and acted as a physical barrier against corrosion.

\section{Fretting results}

Fig. 9 shows the variation of the friction coefficient, $\mu$, as a function of the number of cycles, N, going up to 20000 cycles, for the samples summarized in Table 2. For the untreated CP-Ti grade 4, the average friction coefficient, $\mu$, increased from an initial value of 0.62 up to a value of 1.52, during the first 1200 cycles, and gradually decreased slightly and, thereafter, it was steady. This indicates the gradual erosion of the Cp-Ti grad 4 with the progression of fretting cycles. For the LSA 1 sample, the average friction coefficient, $\mu$, increased up to a value of 1.24 during the first 1300 cycles, and stabilized to a value of about 1.2. For the LSA 2 and LSA 3 samples, the friction coefficient, $\mu$, did not significantly change with the number of fretting cycles during 1300 cycles, but its value was two times lower than the one from CP-Ti grade 4. These results are in agreement with those reported in ref. [24], in the case of titanium plates thermal oxidation.

The formation of a thick oxidized layer at the surface of pure titanium (CP-Ti grade 4) plates, by a laser treatment with a Nd:YAG pulsed laser, was found to improve the fretting of titanium plates by reducing the fretting coefficient, $\mu$ [24]. The surface treatments reduced the value of the friction coefficient of CP-Ti grade 4 . Moreover, the composition and the structure did not significantly modify the value of the friction coefficient above 1300 fretting cycles.

Finally, the reduction in the friction coefficient can also improve the fretting wear resistance. The reason of this improvement may be attributed to the increased hardness, because of the increase in nitrogen $(\mathrm{N})$ content in the treated samples [25].

Fig. 10 shows the SEM images of the typical fretting wear scars generated in untreated and treated specimens after the fretting test (20000 fretting cycles at 20 
$\mathrm{Hz}$, slip amplitude of $\pm 90 \mu \mathrm{m}$, normal load of $18 \pm 2 \mathrm{~N}$ ). All the scars were oval. The untreated specimen showed significant evidence of wear debris formation on one side of the wear scar. The wear debris appeared to have been adhered to the specimen surface, probably due to the combined effects of shear and compressive stresses imparted by the counter surface.

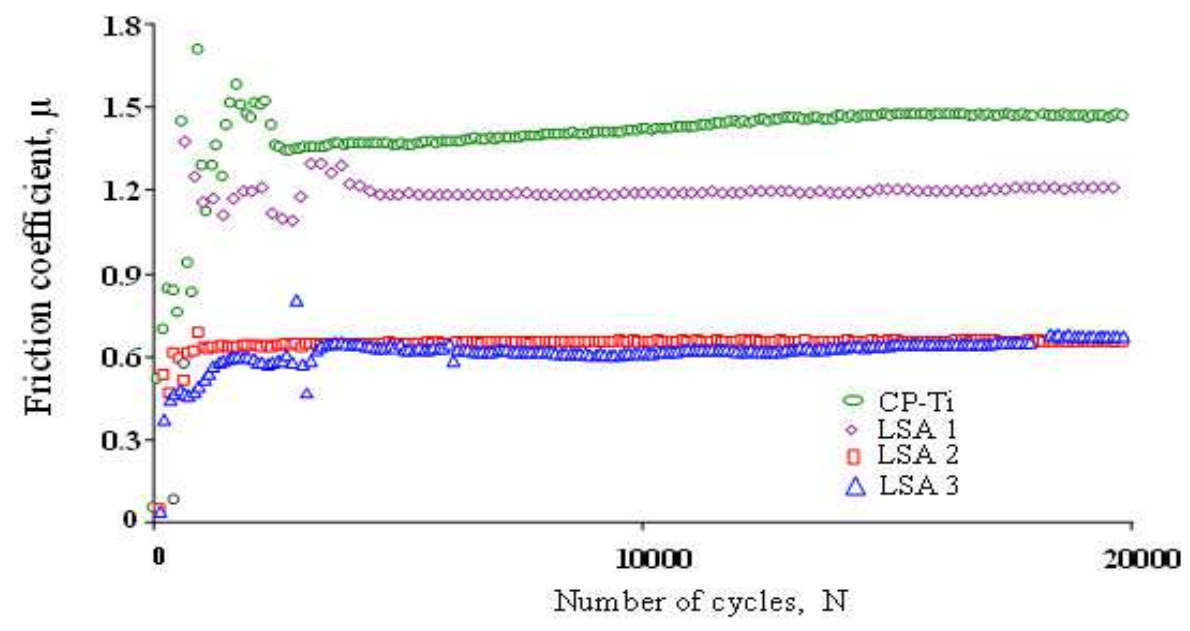

Figure 9. Evolution of the friction coefficient, $\mu$, with the number of fretting cycles, N, of Cp-Ti grade 4, before and after laser treatments.

The study of the fretting scars formed in the different samples surfaces revealed a high resistance of LSA 3 sample to fretting wear.

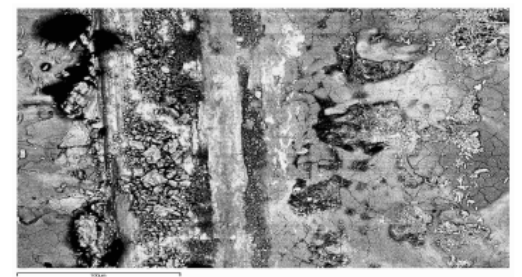

a)

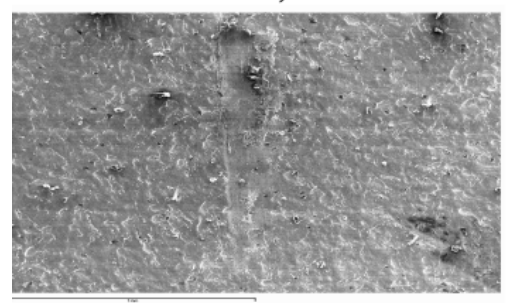

(c)

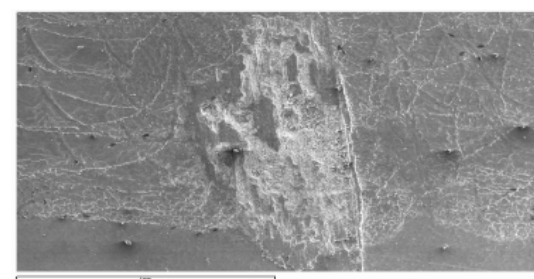

b)

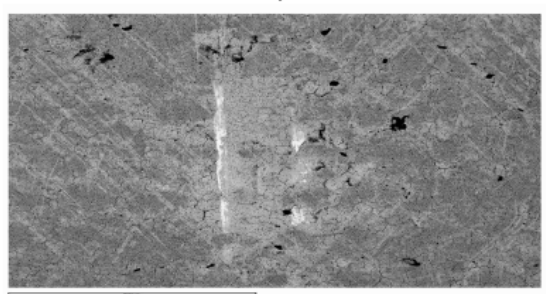

(d)

Figure 10. SEM surface images of the fretting wear scars of the untreated Cp-Ti grade 4 (a), LSA 1 (b), LSA 2 (c) and LSA 3 (d) specimens after the fretting test (20000 fretting cycles at $20 \mathrm{~Hz}$, slip amplitude of $\pm 90 \mu \mathrm{m}$, normal load of $18 \pm 2 \mathrm{~N}$ ).

\section{Conclusions}

The laser treatment of titanium CP-Ti grade 4 by pulsed laser irradiation in air, using a Nd:YAG Q-switched laser of short pulse duration of about $5 \mathrm{~ns}$, gave rise to colored surface layers. 
The changes in the morphology, structure and chemical composition of the treated layers were studied by SEM, EDS and X-ray diffraction (XRD). It was shown that the laser treatment induced the insertion of light elements such as $\mathrm{O}$ and $\mathrm{N}$ in the formed layers.

The laser surface processing shifted the corrosion potential of CP-Ti grade 4 towards the noble side, as compared to the untreated one. The best corrosion resistance was observed for the optimum dose of nitrogen in the obtained layers. The reduction in the friction coefficient could also improve the fretting wear resistance. The reason of this improvement may be attributed to the increased hardness, because of the increase in nitrogen $(\mathrm{N})$ content in the treated samples. Finally, the study of the fretting scars formed in the different samples surface revealed a high resistance of LSA 3 sample to fretting wear.

\section{Acknowledgements}

The authors address special acknowledgments to all members of Ltm laboratory (Institut Carnot de Bourgogne).

\section{References}

1. Ochonogor OF, Meacock C, Abdulwahab M, et al. Effects of Ti and TiC ceramic powder on laser-cladded Ti-Al-4C in situ intermetallic composite, Effects of $\mathrm{Ti}$ and $\mathrm{TiC}$ ceramic powder on laser-cladded $\mathrm{Ti}-\mathrm{Al}-4 \mathrm{C}$ in situ intermetallic composite. Appl Surf Sci. 2012;263:591-596.

2. Torrent F, Lavisse L, Berger $\mathrm{P}$, et al. Influence of the composition of titanium oxynitride layers on the fretting behavior of functionalized titanium substrates: PVD films versus surface laser treatments. Surf Coat Technol. 2014;255:146-152.

3. Lavisse L, Berger P, Cirisan M, et al. Influence of laser- target interaction regime on composition and properties of surface layers grown by laser treatment of Ti plates. J Phys D: Appl Phys. 2009;42:245-303.

4. Liu Y, Tang S, Liu G, et al. Electrochemical impedance spectroscopy characteristic of Ti-6Al-4V alloy with and without welding under the different load model. Int J Electrochem Sci. 2016;11:8530-8545.

5. Petrovic S, Radak B, Perusko D, et al. Laser-induced surface alloying in nanosized Ni/Ti multilayer structures. Appl Surf Sci. 2013;264:273-279.

6. Manna I, Dutta Majumdar J, Ramesh Chanda B, et al. Laser surface cladding of Fe-B-C, Fe-B-Si and Fe-BC-Si-Al-C on plain carbon steel. Surf Coat Technol. 2006;201:434-440.

7. Langlade C, Vannes AB, Krafft JM, et al. Surface modification and tribological behavior of titanium and titanium alloys after YAG laser treatments. Surf Coat Technol. 1998;383:100-101.

8. Perez del Pino A, Serra P, Morenza JL. Coloring of titanium by pulsed laser processing in air. Thin Solid Films. 2002;415:20-201.

9. Santos EC, Morita M, Shiomi M, et al. Laser gas nitriding of pure titanium using CW and pulsed Nd: YAG lasers. Surf Coat Technol. 2006;201:16351642. 
10. György E, Perez del Pino A, Serra P, et al. Surface Nitridation of titanium by pulsed Nd:YAG laser irradiation. Appl Surf Sci. 2002;186:130-134.

11. Höche D, Schikora H, Zutz H, et al. TiN- coating formation by pulsed $\mathrm{Nd}$ :YAG laser irradiation of titanium in nitrogen. $J$ Coat Technol Res. 2008;5:505-512.

12. Lavisse L, Jouvard JM, Gallien JP, et al. The influence of laser power and repetition rate on oxygen and nitrogen insertion into titanium using pulsed Nd:YAG laser irradiation. Appl Surf Sci. 2007;254:916.

13. Shidid DP, Hoseinpour Gollo M, Brandt M, et al. Study of effect of process parameters on titanium sheet metal bending using Nd:YAG laser. Opt Laser Technol. 2013;47:242-247.

14. Assist SL, Wolynec S, Costa I. Corrosion characterization of titanium alloys by electrochemical techniques. Electrochim Acta. 2006;51:1815-1819.

15. Assist SL, Costa I. Electrochemical evaluation of Ti-13Nb-13 Zr, Ti- Al-4V and Ti-6Al-7Nb alloys for biomedical application by long-term immersion tests. Mater Corros. 2007;58:329-333.

16. Majumdar P, Singh SB, Chatterjee UK, et al. Corrosion behavior of treated boron free and boron containing Ti-13Zr-13Nb (wt\%) alloy in simulated body fluid. J Mater Sci Med. 2011;22:797-80.

17. Jakubowicz J, Adamek G, Jurczyk MU, et al. 3D surface topography study of biofunctionalized nanocrystalline Ti-6Zr-4Nb/Ca-P. Mater Charact. 2012;70:55-62.

18. Calderon Moreno JM, Vasilescu E, Osiceanu P, et al. Surface and electrochemical characterization of a new ternary titanium based alloy behavior in electrolytes of varying $\mathrm{pH}$. Corros Sci. 2013;77:52-63.

19. Pelletier JM, Sauger E, Gachon Y, et al. Mechanical and tribological properties of Hadfield steel coatings manufactured by laser processing. J Mater Sci. 1999;34:2955-2969.

20. Singh R, Chowdhury G, Tiwari SK, et al. Laser surface processing of Ti6Al4V in gaseous nitrogen: corrosion performance in physiological solution. J Mater Sci: Mater Med. 2008;19:1363-1369.

21. Puerta Velasquez JD, Lavisse L, Kneip JC, et al. Thermal effects of continuous laser treatment on $\mathrm{Ti}-6 \mathrm{Al}(\mathrm{wt} \%)-4 \mathrm{~V}(\mathrm{wt} \%)$ titanium alloy. Mat Sci. 2008;595:1033-1038.

22. Lavisse L, Grevy D, Langlade C, et al. The early stage of the laser-induced oxidation of titanium substrates. Appl Surf Sci. 2002;186:150-155.

23. Ageev El, Andreeva YaM, Karlagina YuYu, et al. Composition analysis of oxide films formed on titanium surface under pulsed laser action by method of chemical thermodynamics. Laser Phys. 2017;27:046001.

24. Marco de Lucas MC, Lavisse L, Pillon G. Microstructural and tribological study of Nd:YAG laser treated titanium plates. Tribol Int. 2008;4:985-991.

25. Liu L, Shangguan YJ, Tang HB, et al. Fretting wear behavior of laser-nitred Ti-5Al-5Mo-5V-1Cr-1Fe alloy fabricated by laser melting deposition. Appl Phys A. 2014;339:83-81. 